\title{
Improve Shoot Proliferation of Nodal Segments of Jojoba (Simmondsia chinensis Schneider) Genotypes by Growth Regulators Combinations
}

\author{
Amr S.Mohamed ${ }^{1-2}$, Magdi A.A. Mousa ${ }^{1}$ and Ahmed A. S. Bakhashwain ${ }^{1}$ \\ ${ }^{1}$ Department of Arid Land Agriculture, Faculty of Meteorology, Environment and Arid Land \\ Agriculture, King Abdulaziz University, Jeddah, Saudi Arabia and ${ }^{2}$ Depatment of Olive and Semi- \\ Arid Land Fruits Research, Agriculture Research Center, Giza, Egypt.
}

\begin{abstract}
The effect of plant growth regulates on in vitro nodal segments of four jojoba genotypes were investigated. Shoot initiation was performed using MS medium supplemented with BAP in combinations with NAA, IAA and 2,4- D. The experiments were conducted using the completely Randomized design (CRD) and 4 replicates. The results of in vitro nodal segments indicated that the culture medium without growth regulators (MS0), $\mathrm{MS}+5 \mathrm{mg} / \mathrm{l}-1 \mathrm{BAP}, \mathrm{MS}+3 \mathrm{mg} / \mathrm{l}-1 \mathrm{BAP}+5 \mathrm{mg} / \mathrm{l}-1 \mathrm{IAA}, \mathrm{MS}+5 \mathrm{mg} / \mathrm{l}-1 \mathrm{BAP}+$ $7 \mathrm{mg} / \mathrm{l}-1 \mathrm{NAA}$ and $\mathrm{MS}+7 \mathrm{mg} / 1-1 \mathrm{BAP}+7 \mathrm{mg} / \mathrm{l}-1 \mathrm{NAA}$ significantly decreased number of days to sprouting, increased $\%$ of sprouted buds. The culture medium MS $+7 \mathrm{mg} / 1-1$ BAP $+7 \mathrm{mg} / 1-1$ NAA produced the highest no. of leaves/shoot, length of primary shoots and no. of nodes/shoot. Explants of the genotype 'Hail-B' registered the highest no. of days for bud sprouting. The genotypes 'Hail-A' and 'AlMadinha' produced the highest percentage of sprouted buds, no. of leaves/shoot, length of primary shoots (cm) and no. of nodes/shoot. The jojoba genotypes 'Hail A', 'Al-Madinah' and 'Hada Al-Sham' were the most useful genotypes for micropropagation using nodal segments. The MS media supplemented with $5 \mathrm{mg} / \mathrm{L}-1$ BAP alone or with $3 \mathrm{mg} / \mathrm{L}-1$ BAB and $5 \mathrm{mg} / \mathrm{L}-1$ IAA can be applied for jojoba micropropagation using nodal segments explants.
\end{abstract}

Keywords: nodal segment, jojoba, growth regulators, shoot proliferation.

\section{Introduction}

Micropropagation is a tissue culture technique suited to the multiplication of elite crops by using explants of the plant leaf, root, and steam. The major advantageous of this technique are the production of pathogen-free plants, can be used for genetic improvement of the species and provide a commercial production within a restricted time and space (Agrawal, et al., 2002; Bashir, et al., 2007c). Several studies have been done to propagate jojoba in vitro using various explants tissues and culture media supplemented with different concentrations of plant growth regulators
(PGRs) (Khanam, et al., 1999; Prakash, et al., 2003; Tyagi and Prakash, 2004; Bashir, et al., 2007c). Generally, MS and B5 media supplemented with a combination of cytokines (BA, Kinetin and zeatin) and auxines (NAA, IAA, IBA) have been frequently used (Agrawal, et al., 2002; Bashir, et al., 2008). The genotypes/clones differ in their response when cultured in vitro (Llorente and Apostolo, 1998). Prakash et al., (2003) found that, BA (alone) was found better than kinetin (alone) or BA + kinetin for in vitro shoot initiation of jojoba. The lower concentration of BA proved more effective for many shoot parameters (Bashir et al., 2007c). MS media 
supplemented with BA and GA3 enhanced Shoot initiation of Jojoba while MS + IBA supported root formation (Heba et al, 2009). Bud initiation and shoot multiplication were found to be greatest on Murashige and Skoog's (MS) medium supplemented with BA and adenine (Singh, et al., 2008). Encapsulated buds exhibited the best shoot development on Murashige and Skoog (MS) medium supplemented with $1.0 \mathrm{mg} / \mathrm{L}$ BA, $40 \mathrm{mg} / \mathrm{L}$ adenine sulfate and $3.0 \mathrm{mg} / \mathrm{l}$ IAA and gelled with $0.8 \%$ bacteriological agar $(73 \%+5.17$ conversion) (Hasan 2003). Jojoba (Simmondsia chinensis) is a perennial evergreen, dioecious and an obligated cross pollinated shrub (Benzioni, 1995). Because of its low water requirement, root system and economical potential, jojoba was introduced to cultivation in various semi-arid and arid regions of the world. Jojoba was introduced first time in Saudi Arabia in 1993 (Osman, et al., 1997), however, there is no information available about the total cultivated area, total production and productivity of jojoba in Saudi Arabia (Faostate, 2010). The Jojoba seeds contain about $50-55 \%$ distinctive oil which commonly known as liquid wax. The oil of jojoba was considered to be stable under pressure and high temperature, un-saturated and simple on the molecular base. These characteristics amenable the jojoba oil to use commercially in the cosmetic, pharmaceutical and lubricant industries (Gentry 1958). Sexual propagation of Jojoba dose not reproduce true to type plants and asexual propagation of single jojoba plant is necessary to conserve the desirable traits. Several asexual propagation techniques were used to reproduce Jojoba i.e. layering (Reddy, 2003; Bashir et al., 2005), grafting (Bashir et al., 2006), and cuttings (Singh et al., 2003; Bashir et al., 2007a). However, the availability of a maximum number of possible propagules and seasonal propagation are the major challenges of these techniques. The present study aims to consider the influences of plant growth regulators on in vitro nodal segments of four jojoba genotypes.

\section{Materials and Methods}

Preparation and sterilization of nodal
segments

The present investigation was conducted using four jojoba genotypes called 'Hail A', 'Medina', 'Hail B' and 'Hada Al-sham', cultivated in the western region of Saudi Arabia (Mousa and Bakhashwain, 2014). The $1-2 \mathrm{~cm}$ nodal segments were prepared from the one year established branches on the 5 years old jojoba plants. The branches were divided to small pieces each contains from 2 to 3 nodes. The leaves were removed keeping the petiole intact. The branches pieces were subjected to a sterilization protocol as following: a) thoroughly washed in running tap water for $30 \mathrm{~min}, \mathrm{~b}) 1-2.0 \mathrm{~cm}$ long nodal segments were dipped in $98 \%$ ethanol $(\mathrm{v} / \mathrm{v})$ for $5-10 \mathrm{~s}, \mathrm{c})$ then dipped in $10 \%$ Clorox $(\mathrm{v} / \mathrm{v})$ solution +2 drops of Tween-20 for $15 \mathrm{~min}, \mathrm{~d}$ ) followed by four washings with sterile distilled water, each for $5 \mathrm{~min}$, and e) the explants were dipped in $0.1 \%$ mercuric chloride $(\mathrm{w} / \mathrm{v})$ solution for $15 \mathrm{~min}$ and subsequently washed 4 times in sterile distilled water each for $5 \mathrm{~min}$. The sterilization steps from $b$ to $\mathrm{e}$ were conducted in a laminar air flow hood.

\section{MS-Basel medium and plant growth regulators}

All experiments were conducted in 2012/2013 at the lab. of plant tissue culture, Department of Arid Land Agricultute, King Abdulaziz University. The experiments were laid out in Completely Randomized Design (CRD) using 4 replicates. The experiments were designed to study the effects of growth regulators on nodal segments of jojoba. The explants (nodal segments) were cultured on MS medium (Murashige and Skoog, 1962) containing $30 \mathrm{~g} / 1$ sucrose, $7.5 \mathrm{~g} / \mathrm{l}$ agar and $0.5 \mathrm{~g}$ Activated Charcoal (AC). The growth regulators combinations supplied to the culture 
medium were presented in table (1). .The $\mathrm{pH}$ of the media was adjusted to 5.8 prior to adding agar. The media were autoclaved at $121 \mathrm{oC}$ and $1.05 \mathrm{~kg} \mathrm{~cm}-2$ for $15 \mathrm{~min}$. The plant growth regulators were added to the autoclaved media through membrane filters (Millex-GS $0.22 \mu \mathrm{m}$ filter unit) under controlled conditions. Media were handed out in $12 \mathrm{ml}$ into culture tubes, which were plugged with a thermo lid and the lids were bundled with one layer of parafilm (Pechiney Plastic Packaging, Chicago, IL.60631). The nodal segments were cultured on the culture media under laminar air flow hood. Four explants were cultured from each treatment per replication (one explants/ test tube). The cultured tubes were incubated under $16 \mathrm{~h}$ light (white fluorescent light with intensity of 55 $\mu \mathrm{mol} \mathrm{m}-2 \mathrm{~s}-1)$ and $8 \mathrm{~h}$ dark, and the temperature was $24 \pm 1 \mathrm{oC}$. A sub-culturing at 6 weeks interval was applied onto fresh medium of the same composition to preserve the cultures.

\section{Assessed Parameters}

The following parameters were estimated: no. of days to bud sprouting, $\%$ of sprouted buds, no. of leaves/shoot, no. of nodes/shoot and length of primary shoot $(\mathrm{cm})$.

\section{Data Analysis}

The experiment was conducted in a 2 factors Completely Randomized design (CR) using 4 replications. Analysis of variance relevant to $\mathrm{CR}$ experiments as described by Gomez and Gomez, (1984), were conducted. The treatment means were compared by employing Least Significant Differences (LSD) test at 5\% probability (Steel and Torrie, 1984).

\section{Results}

No. of days to bud sprouting

There were observed significant differences due to effects of genotypes, plant growth regulators and their interactions on in vitro nodal segments of jojoba at all measured traits except days to bud sprouting (Table 2). The growth regulators were divided into two clusters based on their effects on percentage of bud sprouting. The first cluster contained the culture medium that significantly decreased no. of days to bud sprouting including MS/NS1 (MS0) with 9.75 days, MS/NS2 (MS + 5 mg.l-1 BAP ) with 9.58 days, MS/NS7 (MS + 5 mg.1-1 BAP + 7 mg.1-1 NAA ) with 9.50 days and MS/NS19 (MS+ 7 mg.1-1 BAP +7 mg.1-1 NAA ) with 9.08 days (Table 3). The second cluster included the culture medium that significantly increased number of days to bud sprouting including MS/NS8 (MS + 5 mg.1-1 BAP + 7 mg.1-1 2.4-D ) (29.91 days), MS/NS6 (MS + 5 mg.1-1 BAP + 7 mg.11 IAA) (28.33 days), MS/NS3 (MS + 5 mg.1-1 BAP +3 mg.1-1 IAA) (26.91 days), MS/NS18 (MS+ 7 mg.l-1 BAP + 7 mg.l-1 IAA) (26.33 days), MS/NS9 (MS + 3 mg.l-1 BAP + 5 mg.1-1 IAA) (26.08 days) and MS/NS12 (MS +3 mg.1-1 BAP + 7 mg.1-1 IAA) (24.33 days) (Fig. 1A).

Table 1. Treatments applied to study the effects of plant growth regulators and sucrose on in vitro nodal segments and shoot tip culture of jojoba.

\begin{tabular}{|c|c|}
\hline \multicolumn{2}{|l|}{$\begin{array}{l}\text { Treatments } \\
\text { Code }\end{array}$} \\
\hline MS0 & $\mathrm{MS} / \mathrm{NS} 1^{1}$ \\
\hline $\mathrm{MS}+5 \mathrm{mg} / \mathrm{L}-1 \mathrm{BAP}$ & $\mathrm{MS} / \mathrm{NS} 2$ \\
\hline $\begin{array}{l}\mathrm{MS}+3 \mathrm{mg} / \mathrm{L}-1 \mathrm{BAP}+5 \mathrm{mg} / \mathrm{L}-1 \\
\mathrm{IAA}\end{array}$ & $\mathrm{MS} / \mathrm{NS} 3$ \\
\hline $\mathrm{MS}+3 \mathrm{mg} / \mathrm{L}-1 \mathrm{BAP}+7 \mathrm{mg} / \mathrm{L}-1 \mathrm{IAA}$ & MS/NS4 \\
\hline $\mathrm{MS}+5 \mathrm{mg} / \mathrm{L}-1 \mathrm{BAP}+3 \mathrm{mg} / \mathrm{L}-1 \mathrm{IAA}$ & MS/NS5 \\
\hline $\mathrm{MS}+5 \mathrm{mg} / \mathrm{L}-1 \mathrm{BAP}+7 \mathrm{mg} / \mathrm{L}-1 \mathrm{IAA}$ & MS/NS6 \\
\hline $\mathrm{MS}+7 \mathrm{mg} / \mathrm{L}-1 \mathrm{BAP}+7 \mathrm{mg} / \mathrm{L}-1 \mathrm{IAA}$ & MS/NS7 \\
\hline $\begin{array}{l}\mathrm{MS}+5 \mathrm{mg} / \mathrm{L}-1 \mathrm{BAP}+7 \mathrm{mg} / \mathrm{L}-1 \\
\mathrm{NAA}\end{array}$ & MS/NS8 \\
\hline $\begin{array}{l}\mathrm{MS}+7 \mathrm{mg} / \mathrm{L}-1 \mathrm{BAP}+7 \mathrm{mg} / \mathrm{L}-1 \\
\mathrm{NAA}\end{array}$ & MS/NS9 \\
\hline $\begin{array}{l}\mathrm{MS}+5 \mathrm{mg} / \mathrm{L}-1 \mathrm{BAP}+7 \mathrm{mg} / \mathrm{L}-1 \\
2.4-\mathrm{D}\end{array}$ & $\mathrm{MS} / \mathrm{NS} 10$ \\
\hline
\end{tabular}

$1 \mathrm{NS}=$ Nodal Segment culture 
Regarding genotypic effects on number of days to bud sprouting, the highest number of days to bud sprouting was observed for genotype 'Al-Madinah'(21.40) without significant differences from 'Hail-B' (20.06) (Table 3). The jojoba genotypes 'Hada AlSham' (19.13) and 'Hail-A' (19.33) recorded the highest no. of days to bud sprouting with no significant differences. There were observed non-significant interaction between the jojoba genotypes and the applied growth regulators on number of days to bu sprouting. However, explants of the jojoba genotype 'AlMadinah' required higher number of days to bud emerges on culture media MS/NS8 (MS+ 5 mg.1-1 BAP + 7 mg.1-1 2.4-D). The least days to bud emerges were obtained by genotypes 'Al-Madinah' and 'Hail-A' with MS/NS7 (MS + 5 mg.l-1 BAP + 7 mg.l-1 NAA) and genotypes 'Hada Al-Sham', 'Hail$A$ ' and 'Hail-B' with MS/NS8 (MS+5 mg.l-1, BAP+7mg.1-1 2.4-D) (Fig. 1A).

\section{Percentage of sprouted buds}

Regarding percentage of sprouted buds, significant differences between the applied growth regulators and tested genotypes and their interaction were observed. The genotype 'Hail-A' attained highest percentage of sprouted buds $(65.26 \%)$ followed by 'AlMadinah' (58.50\%) and 'Hail-B' (57.53\%). Explants of the jojoba genotype 'Hada AlSham' attained the least percentage of sprouted buds with $54.03 \%$ (Table 3 ).

Table 2. Mean of square of the effects of plant growth regulators and genotypes on in vitro nodal segments of jojoba (Simmondsia Chinensis Schneider).

\begin{tabular}{|c|c|c|c|c|c|c|}
\hline $\begin{array}{l}\text { Source of } \\
\text { Variance }\end{array}$ & $\begin{array}{l}\mathrm{d} \\
\mathrm{f}\end{array}$ & $\begin{array}{l}\text { days } \\
\text { to bud } \\
\text { sprout } \\
\text { ing }\end{array}$ & $\begin{array}{c}\% \\
\text { sprouti } \\
\text { ng }\end{array}$ & $\begin{array}{c}\text { no. } \\
\text { leaves } \\
\text { / shoot }\end{array}$ & $\begin{array}{l}\text { Length } \\
\text { of } \\
\text { primary } \\
\text { shoot } \\
(\mathrm{cm})\end{array}$ & $\begin{array}{c}\text { no.no } \\
\text { de / } \\
\text { shoot }\end{array}$ \\
\hline Rep. & 3 & $\underset{\mathrm{ns}}{31.63}$ & $\begin{array}{c}3718.9 \\
3 \\
\end{array}$ & $2.03^{*}$ & $11.34^{* * *}$ & $\begin{array}{c}2.62^{* *} \\
*\end{array}$ \\
\hline $\begin{array}{l}\text { Growth } \\
\text { Regulator } \\
\text { s (GR) }\end{array}$ & $\begin{array}{l}1 \\
0\end{array}$ & $\begin{array}{l}1006 \\
01^{* * *}\end{array}$ & $\begin{array}{c}4047.2 \\
4^{* * *}\end{array}$ & $5.71^{* *}$ & $10.28^{* * *}$ & $\begin{array}{c}2.20^{* *} \\
*\end{array}$ \\
\hline $\begin{array}{c}\text { Rep. X } \\
\text { GR }\end{array}$ & $\begin{array}{l}1 \\
8 \\
\end{array}$ & $\underset{*}{52.72}$ & $\underset{\mathrm{ns}}{405.86}$ & $0.96^{* *}$ & $0.711^{\mathrm{ns}}$ & $0.20^{\mathrm{ns}}$ \\
\hline $\begin{array}{c}\text { Jojoba } \\
\text { Genotype } \\
\text { s (JG) } \\
\end{array}$ & 3 & $\underset{\mathrm{ns}}{31.58}$ & $\underset{\text { ns }}{662.28}$ & $5.35^{* * *}$ & $9.12^{* * *}$ & $\begin{array}{c}1.85^{*} \\
* *\end{array}$ \\
\hline GR. X JG & $\begin{array}{l}3 \\
0 \\
\end{array}$ & $\underset{\text { ns }}{24.16}$ & $\underset{* * *}{854.19}$ & $1.57^{* * *}$ & $1.82^{* * *}$ & $\begin{array}{c}0.68^{* *} \\
*\end{array}$ \\
\hline Error & $\begin{array}{l}6 \\
0 \\
\end{array}$ & 24.67 & 276.93 & 0.316 & 0.43 & 0.19 \\
\hline
\end{tabular}

${ }^{\mathrm{ns}}$ not significant.

$*, * *, * * *$ significant at $\mathrm{p} \leq 0.05,0.01,0.001$. 
Table 3. Means of days to bud sprouting shoot formation, number of leaves/shoot, length of primary shoot and number of nodes/shoot of in vitro propagated jojoba using nodal segments as affected by genotypes and growth regulators combinations.

${ }^{1}$ means fallowed by same letters are not significantly different according to $\operatorname{LSD} \mathrm{P} \leq 0.05$. ${ }^{2 *}, * *, * * *$ significant at $\mathrm{p} \leq 0.05,0.01,0.001 .{ }^{3} \mathrm{NS}$ : non significant.

Among the tested plant growth regulators combinations, the culture medium MS/NS2 (MS + 5 mg.l-1 BAP) increased percentage of sprouted buds (85.91\%) followed by MS/NS1 (MS0) with 83.08\% and MS/NS9 (MS + 3 mg.l-1 BAP + 5 mg.1-1 IAA ) with $80.33 \%$. The culture medium MS/NS8 (MS + 5 mg.1-1 BAP + 7 mg.l-1 2.4-D) registered the least percentage of sprouted buds (38.50\%).

Concerning interaction between growth regulators and jojoba genotypes, the nodal segments of jojoba genotype 'Hail-B' registered the highest percentage of sprouted buds on the culture medium MS/NS1 (MS0) followed by 'Al-Madinah' with culture medium MS/NS2 (MS + 5 mg.1-1 BAP) and 'Hail-A' with culture medium MS/NS9 (MS + 3 mg.1-1 BAP + 5 mg.1-1 IAA ) (Fig. 1B).

The least percentages of emerged buds were produced by genotypes 'Hail-B' with the culture medium MS/NS12 (MS + 3 mg.1-1 BAP + 7 mg.1-1 IAA), MS/NS3 (MS + 5 mg.11 BAP + 3 mg.1-1 IAA), MS/NS18 (MS+ 7 mg.1-1 BAP + 7 mg.1-1 IAA), MS/NS7 (MS +

\begin{tabular}{|c|c|c|c|c|c|}
\hline $\begin{array}{l}\text { Treat } \\
\text { ments }\end{array}$ & $\begin{array}{l}\text { Days to } \\
\text { bud } \\
\text { sprouti } \\
\text { ng }\end{array}$ & $\begin{array}{c}\text { Bud } \\
\text { sprouti } \\
\text { ng } \\
(\%)\end{array}$ & $\begin{array}{c}\text { No. of } \\
\text { leaves/ } \\
\text { shoot }\end{array}$ & $\begin{array}{c}\text { Lengt } \\
\text { h of } \\
\text { prima } \\
\text { ry } \\
\text { shoot } \\
\text { (cm) }\end{array}$ & $\begin{array}{l}\text { No. of } \\
\text { nods/ } \\
\text { shoot }\end{array}$ \\
\hline \multicolumn{6}{|c|}{ Growth Regulators (GR) } \\
\hline $\begin{array}{l}\text { MS/NS } \\
1\end{array}$ & $9.75 b^{1}$ & $83.08 \mathrm{a}$ & $3.66 \mathrm{~cd}$ & $8.58 b c$ & $\begin{array}{c}1.91 \mathrm{bc} \\
\mathrm{d}\end{array}$ \\
\hline $\begin{array}{l}\text { MS/NS } \\
2\end{array}$ & $9.58 b$ & $85.91 \mathrm{a}$ & $2.66 \mathrm{~d}$ & $11.50 \mathrm{~b}$ & $1.50 \mathrm{~cd}$ \\
\hline $\begin{array}{l}\text { MS/NS } \\
9\end{array}$ & $26.08 \mathrm{a}$ & $\begin{array}{c}80.33 a \\
b\end{array}$ & $8.08 \mathrm{a}$ & $15.58 \mathrm{a}$ & $3.83 \mathrm{a}$ \\
\hline $\begin{array}{l}\text { MS/NS } \\
12\end{array}$ & $24.33 \mathrm{a}$ & $\begin{array}{c}55.25 \mathrm{c} \\
\mathrm{d}\end{array}$ & 7.33ab & $11.83 b$ & $3.75 \mathrm{a}$ \\
\hline $\begin{array}{l}\text { MS/NS } \\
3\end{array}$ & 26.91a & $\begin{array}{c}46.83 \mathrm{c} \\
\mathrm{d}\end{array}$ & $6.66 \mathrm{abc}$ & $6.66 \mathrm{~cd}$ & $3.33 \mathrm{ab}$ \\
\hline $\begin{array}{l}\text { MS/NS } \\
6\end{array}$ & $28.33 \mathrm{a}$ & $\begin{array}{c}63.58 b \\
c\end{array}$ & $\begin{array}{c}3.91 \mathrm{bc} \\
\mathrm{d}\end{array}$ & $6.33 \mathrm{~cd}$ & $2.00 \mathrm{bc}$ \\
\hline $\begin{array}{l}\text { MS/NS } \\
18\end{array}$ & $26.33 a$ & $41.25 \mathrm{~d}$ & $0.91 \mathrm{~d}$ & $1.58 \mathrm{e}$ & $0.50 \mathrm{~d}$ \\
\hline $\begin{array}{l}\text { MS/NS } \\
7\end{array}$ & $9.50 \mathrm{~b}$ & $\begin{array}{c}52.25 \mathrm{c} \\
\mathrm{d}\end{array}$ & $1.66 \mathrm{~d}$ & 4.16de & $0.83 \mathrm{~cd}$ \\
\hline $\begin{array}{l}\text { MS/NS } \\
19\end{array}$ & $9.08 \mathrm{~b}$ & $41.33 \mathrm{~d}$ & $0.41 \mathrm{~d}$ & $2.50 \mathrm{e}$ & $0.50 \mathrm{~d}$ \\
\hline $\begin{array}{l}\text { MS/NS } \\
8\end{array}$ & $29.9 a$ & $38.50 \mathrm{~d}$ & $1.66 \mathrm{~d}$ & $4.00 \mathrm{de}$ & $1.08 \mathrm{~cd}$ \\
\hline F test & $* * * 2$ & $* * *$ & $* * *$ & $* * *$ & $* *$ \\
\hline LSD & 6.228 & 17.279 & 3.596 & 3.336 & 1.475 \\
\hline \multicolumn{6}{|c|}{ Jojoba Genotypes (JG) } \\
\hline $\begin{array}{l}\text { Hada } \\
\text { Al- } \\
\text { sham }\end{array}$ & $19.13 \mathrm{a}$ & $54.03 \mathrm{~b}$ & $4.20 \mathrm{a}$ & $7.90 \mathrm{a}$ & $2.10 \mathrm{a}$ \\
\hline $\begin{array}{l}\text { Al- } \\
\text { Madin } \\
\text { ah }\end{array}$ & $21.40 \mathrm{a}$ & $\begin{array}{c}58.50 \mathrm{a} \\
\mathrm{b}\end{array}$ & $4.53 \mathrm{a}$ & $8.16 \mathrm{a}$ & $2.23 \mathrm{a}$ \\
\hline Hail-A & $19.33 \mathrm{a}$ & $65.26 \mathrm{a}$ & $4.46 \mathrm{a}$ & $9.36 \mathrm{a}$ & $2.43 \mathrm{a}$ \\
\hline Hail-B & $20.06 \mathrm{a}$ & $\begin{array}{c}57.53 a \\
b\end{array}$ & $1.60 \mathrm{~b}$ & $3.66 \mathrm{~b}$ & $0.93 b$ \\
\hline F test & $\mathrm{NS}^{3}$ & $*$ & $* * *$ & $* * *$ & $* *$ \\
\hline $\begin{array}{l}\text { LSD } \\
(0.05)\end{array}$ & ---- & 8.543 & 1.671 & 2.121 & 0.914 \\
\hline \multicolumn{6}{|c|}{ Interaction } \\
\hline \multicolumn{6}{|l|}{$\mathbf{J G} * \mathbf{G R}$} \\
\hline F test & $* * *$ & $* * *$ & $* * *$ & $* *$ & $* *$ \\
\hline
\end{tabular}


5 mg.1-1 BAP + 7 mg.l-1 NAA), MS/NS19 (MS+ 7 mg.1-1 BAP + 7 mg.1-1 NAA) and MS/NS8 (MS + 5 mg.l-1 BAP + 7 mg.1-1 2.4D). Additionally, low percentage of sprouted buds were produced by the jojoba genotype 'Hail-A' with the culture medium MS/NS18 (MS+ 7 mg.1-1 BAP + 7 mg.1-1 IAA ) and MS/NS8 (MS + 5 mg.l-1 BAP + 7 mg.1-1 2.4D), the genotype 'A-Madinah' with the culture medium MS/NS18 and MS/NS8 (MS + 5 mg.1-1 BAP + 7 mg.1-1 2.4-D), and the genotype 'Hada Al-Sham' with culture medium MS/NS19 (MS+ 7 mg.l-1 BAP + 7 mg.1-1 NAA) and MS/NS8 ((MS + 5 mg.1-1 BAP + 7 mg.1-1 2.4-D) (Fig. 1B).

A

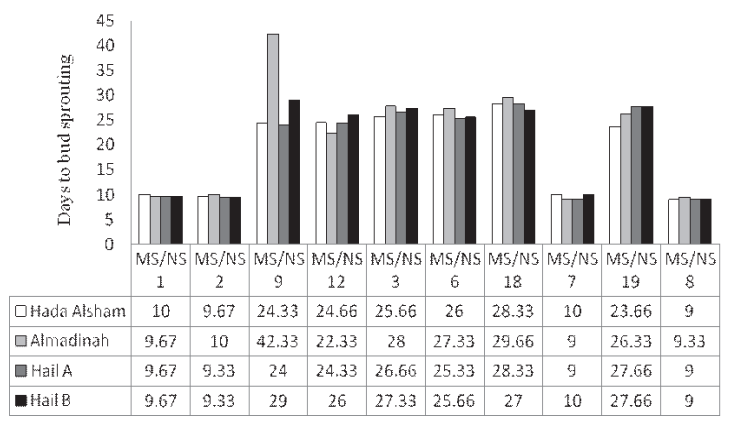

B

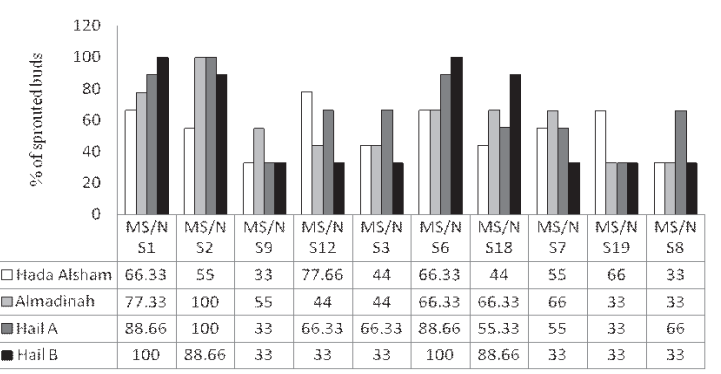

Fig 1. Interaction effects of growth regulators combinations and genotypes on in vitro nodal segments of jojoba: A) no. of days to bud sprouting and B) percentage of sprouted buds/treatment.

\section{Number of leaves/shoot}

Concerning number of leaves/shoot, higher number of leaves/shoot was obtained by the jojoba genotype 'Al-Madenah' leaves/shoot) followed by 'Hail-A' (4.46 leaves/shoot) and 'Hada Al-Sham' with (4.20 leaves/shoot). Decreased number of leaves/shoot was produced by shoots of the jojoba genotype 'Hail-B' with 1.60 leaves/shoot (Table 3). Regarding the applied growth regulators, the culture medium MS/NS9 (MS + 3 mg.1-1 BAP + 5 mg.1-1 IAA) produced the highest number of leaves/shoot with 8.08. Significant decrease in number of leaves/shoots were obtained on the culture medium MS/NS19 (MS+ 7 mg.1-1 BAP +7 mg.1-1 NAA ) with 0.41 followed by MS/NS18 (MS+ 7 mg.l-1 BAP + 7 mg.l-1 IAA) with $0.91, \mathrm{MS} / \mathrm{NS} 8$ (MS $+5 \mathrm{mg} .1-1$ BAP +7 mg.1-1 2.4-D) with 1.66 and MS/NS2 (MS +5 mg.1-1 BAP) with 2.66 (Fig. 2D). About the interaction between the applied growth regulators and jojoba genotypes the results were presented in (Fig. 3A). Cultivating nodal segments of the genotype 'Al-Madinah' on the culture medium MS/NS12 (MS + 3 mg.l-1 BAP + 7 mg.1-1 IAA) resulting exceeded number of leaves/shoot (3.57) followed by 'Hail-A' with the culture medium MS/NS3 (MS + 5 mg.1-1 BAP + 3 mg.1-1 IAA) and MS/NS9 (MS + 3 mg.l-1 BAP + 5 mg.l-1 IAA) with 3.49 and 3.46, respectively (Fig. 3A). On contrary, the least number of leaves/shoots were produced by explants of the jojoba genotypes 'Al-Madinah' with the culture medium MS/NS18 (MS+ 7 mg.l-1 BAP +7 mg.l-1 IAA), 'Hail-A' with the culture medium MS/NS12 (MS + 3 mg.l-1 BAP + 7 mg.l-1 IAA) and 'Hail-B' with the culture medium MS/NS3 (MS + 5 mg.l-1 BAP + 3 mg.l-1 IAA) (Fig 3A).

\section{Length of primary shoot $(\mathrm{cm})$}


The results of effects of growth regulators and jojoba genotypes on average length of primary shoots were presented in Table (3) and Fig. (3B).

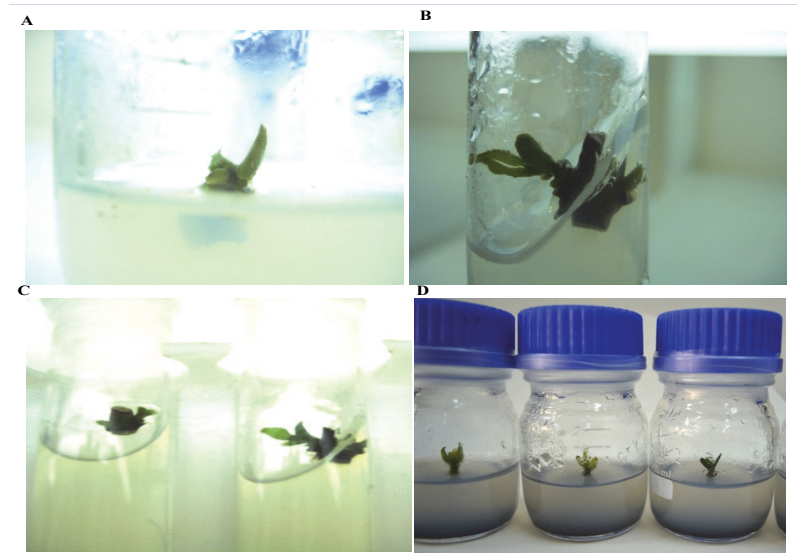

Fig 2. Effects of growth regulators combinations and genotypes on in vitro nodal segments of jojoba: A) no. of days to bud sprouting and B, $C$ and $D)$ percentage of sprouted buds/treatment.

The results significant differences between the tested jojoba genotypes and the applied growth regulators combinations and their interaction with concern the length of primary shoots. The jojoba genotype 'Hail-A' produced the highest length of primary shoot $(2.67 \mathrm{~cm})$ followed by 'Al-Madinah' $(2.57 \mathrm{~cm})$ and 'Hada Al-Sham' $(2.52 \mathrm{~cm})$, while the shortest primary shoots were produced by the genotype 'Hail-B' $(1.49 \mathrm{~cm})$ (Table 3$)$. The culture medium MS/NS9 (MS + 3 mg.1-1 BAP +5 mg.l-1 IAA) with $3.92 \mathrm{~cm}$ registered the highest length of primary shoot followed by MS/NS12 (MS + 3 mg.1-1 BAP + 7 mg.1-1 IAA) with $2.89 \mathrm{~cm}$ and MS/NS1 (MS0) with $2.87 \mathrm{~cm}$. The shortest shoots were $0.93 \mathrm{~cm}$ and produced by jojoba explants on the culture medium MS/NS18 (MS+ 7 mg.l-1 BAP + 7 mg.1-1 IAA). Regarding interaction between the tested jojoba genotypes and the applied growth regulators, explants of the jojoba genotype 'Hada Al-Sham' produced the highest length of primary shoots $(4.33 \mathrm{~cm})$ with the culture medium MS/NS12 (MS + 3 mg.l-1 BAP + 7 mg.1-1 IAA). Whereas, cultivating explants of the jojoba genotype 'Hail-B' on the culture medium MS/NS12 (MS + 3 mg.1-1 BAP + 7 mg.l-1 IAA) and MS/NS3 (MS + 5 mg.1-1 BAP + 3 mg.1-1 IAA) registered the least length of primary shoot $(0.33 \mathrm{~cm})$ (Fig. 3B).

\section{Number of nodes/ shoot}

There were significant differences between the applied growth regulators and jojoba genotypes and their interaction with regards number of nods/shoot. The growth regulators combinations $\mathrm{MS}+3 \mathrm{mg} \cdot 1-1 \mathrm{BAP}+5 \mathrm{mg} .1-1$ IAA (MS/NS9) and MS + 3 mg.1-1 BAP + 7 mg.1-1 IAA (MS/NS12) produced shoots with the highest number of nods (3.83 and 3.33 nods/shoot, respectively). Oppositely, the growth regulators combinations $\mathrm{MS}+7 \mathrm{mg} .1-1$ BAP +7 mg.1-1 IAA (MS/NS18) and MS+ 7 mg.l-1 BAP + 7 mg.l-1 NAA (MS/NS19) reduced significantly the number of nods/shoot (0.50 nodes/shoot for MS/NS18 and MS/NS19) (Table 3). Regarding genotypic effects on number of nods/shoot the results revealed that the jojoba genotypes 'Hail-A' produced higher number of nodes/shoot (2.43) followed by 'Al-Madinah' (2.23) and 'Had AlSham' (2.10). 


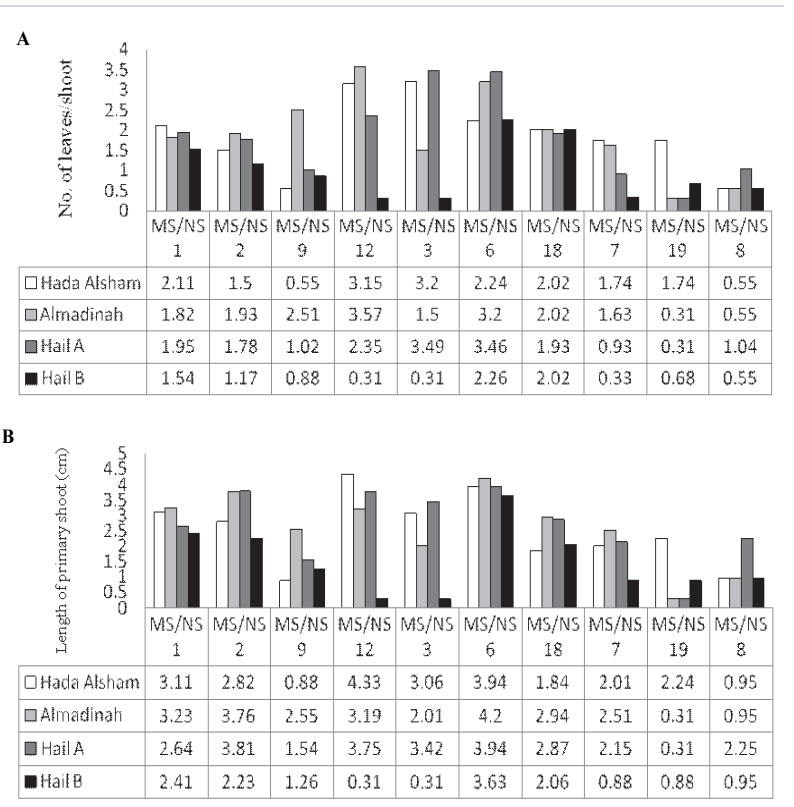

Fig (3): Interaction effects of growth regulators combinations and genotypes on in vitro nodal segments of jojoba: A) no. of leaves/shoot and B) length of primary shoots.

The least number of nods/shoot was produced by the jojoba genotype 'Hail-B' (0.93) (Fig. 4 A-D). About the interaction between growth regulators and jojoba genotypes, the results showed that cultivating explants of the jojoba genotype 'Al-Madinah' on culture medium supplemented with $3 \mathrm{mg} .1-$ 1 BAP +5 mg.1-1 IAA (MS/NS12) resulted the greatest number of nods/shoot (2.58). However, the results were not significant from that was observed when cultivating explants of the jojoba genotype 'Hail-A' on the culture medium MS/NS3 (MS + 5 mg.l-1 BAP + 3 mg.1-1 IAA) and MS/NS6 (MS + 5 mg.1-1 BAP + 7 mg.1-1 IAA) (Fig. 5).

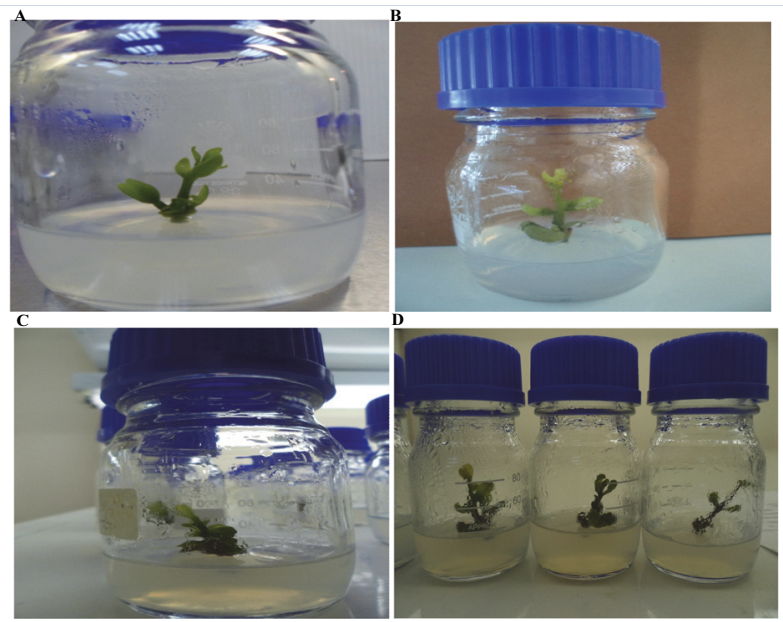

Fig 4. Effects of growth regulators combinations and genotypes on in vitro nodal segments of jojoba: A) jojoba plantlet from 'Al-Madinah' genotype, B) jojoba plantlet from 'Hada Al-Sham' genotype, C) jojoba plantlet from 'Hail-A' genotype and $D$ ) jojoba plantlet from 'Hail-B' genotype.

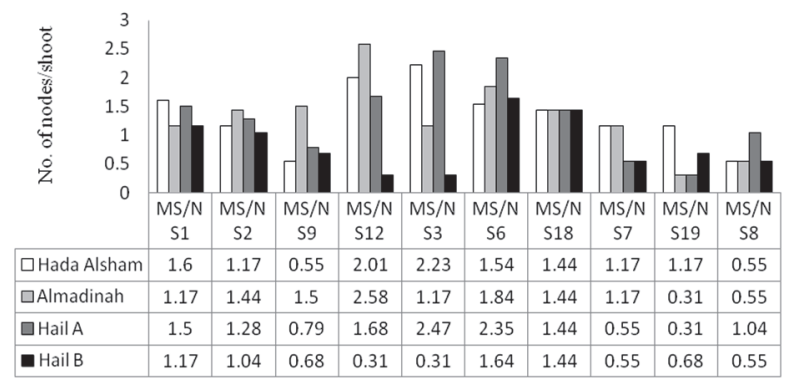

Fig 5. Interaction effects of growth regulators combinations and genotypes on in vitro nodal segments of jojoba: no. of nodes/shoot.

\section{Discussion}

The jojoba genotypes 'Al-Madinah', 'HailA' and 'Hada Al-sham' showed similar highest performance among all tested culture medium for all assessed parameters. These results reflected the ability of these genotypes to micropropagate using nodal segment techniques. Genotype 'Hail-B' showed the least values of assessed parameters among all tested culture medium, which reflected the inappropriateness of this genotype to micropropagate using nodal segments. These results may be attributed to the genetic background of the tested jojoba genotypes. 
The types and concentration of cytokinins/auxins, culture media, explants and genotypes were the most important factors affecting the number of days to bud emergence (Bashir et al 2007; Bashir et al 2008; Heba et al 2009). In the present study the higher concentration of BAP and its combinations with 2,4- D, NAA and IAA were enhanced bud sprouting, however restricted the grow of shoots and leafs of explants. Contrary BAP alone at $5 \mathrm{mg} / \mathrm{L}-1$ (MS/NS2) enhanced bud emergency and increased also the percentage of emerged buds.

Moreover, BAP at $3 \mathrm{mg} / \mathrm{L}-1$ in combination with $5 \mathrm{mg} / \mathrm{L}-1$ IAA increased the number of leafs/shoot, length of primary shoot $(\mathrm{cm})$ and number of nodes/shoot. These result ascribed to the early bud sprouting caused by BAP and BAP in combinations with IAA, which provided adequate time to grow the leafs and shoot than BAP and its combinations with 2,4D, NAA. Regarding shoot tip culture, it is quite clear that shoot tips of jojoba genotypes 'Hail-B' and 'Hada Al-sham' showed similar higher efficiency with all tested culture medium for all assessed parameters. These results showed first indication about the ability of these genotypes to micropropagate using shoot tip culture technique. Genotype 'Hail-B' and 'Al-Madinah' showed the least values of assessed parameters with the tested culture medium.

These results reflected the unsuitability of this genotype to micropropagate using shoot tip culture. As mentioned above the tested genotypes may genetically distinct. Thus they differed in their response to plant growth regulators and shoot tip culture. The culture medium supplemented with $5 \mathrm{mg} / \mathrm{L}-1$ BAP alone (MS/ST2) or with $3 \mathrm{mg} / \mathrm{L}-1$ IAA (MS/St3) revealed the highest values of all assessed parameters. The MS media supplemented with $5 \mathrm{mg} / \mathrm{L}-1 \mathrm{BAP}$ and $5 \mathrm{mg} / \mathrm{L}-$ 1 IAA showed the least values of all assessed traits. The results were partially comparable with that reported by Elhag et al. (1998). They found significant genotypic, PGRs and media types effects on shoot-tip culture of jojoba. Hassan (2003) found that MS medium supplemented with 1mg L-1 BAP, $40 \mathrm{mg}$ L-1 adenine sulfate, $3 \mathrm{mg} \mathrm{L}-1$ IAA and (M2) gave the maximum frequency of conversion of encapsulated buds into plantlets $(73 \%+5.17)$. Bashir et al (2009) reported that BAP + auxins in lower concentrations were increased shoot length than the higher concentrations. Howevere, the results of the presented study were disagreed with the results observed by Sardana and Batra (1998). They observed that the higher concentration of $\mathrm{BA}$ and NAA combinations $(4.4 \mu \mathrm{M}$ BA $+5.4 \mu \mathrm{M}$ NAA) suppressed rooting but increased shoot length of plantlets. Shoot length are affected by cytokinins/auxins ration (Singh and Singh 2005), type of vessels, cultural conditions and plant genotype (Benzioni et al., 2003).

Number of nodes is directly correlated with shoot length. Therefore, the medium concentrations of BAP in combinations with IAA produced the maximum number of nodes/shoots. These results were comparable with that observed by Agrawal et al. (2002). They reported a very few number $(11.5 \%)$ of nodes/shoot from female jojoba clone (EC 33198) when cultured on MS medium supplemented with BA at $20 \mu \mathrm{M}$. Khanam et al (1999) observed that BA + IAA was better than $\mathrm{BA}+\mathrm{NAA}$ in increasing number of nodes/shoot and shoot length, which was in line with the results obtained of the present study.

\section{Conclusion}

The highest percentage of shoot formation, number of leaves/shoot and number of nodes/shoot was obtained with jojoba explants taken in "May" while explants were taken in "August" showed the highest shoot length all 
with genotype 'Al-Madinah'. Regarding the effects of BAP\&GA3 combinations, the MS0 and the MS supplemented with " $1 \mathrm{mg} / \mathrm{l}^{-1} \mathrm{BAP}+$ $1 \mathrm{mg} / \mathrm{l}^{-1} \mathrm{GA} 3+250 \mathrm{mg} / \mathrm{l}^{-1} \mathrm{CH}$ " increased percentage of shoot formation. The culture medium " $1 / 2 \mathrm{MS}+0.5 \mathrm{mg} / \mathrm{l}^{-1} \mathrm{GA} 3$ " produced the lowest percentage of shoot formation and least shoot length and no. of nodes/shoot. The culture medium supplemented with " $1 \mathrm{mg} / \mathrm{l}^{-}$ ${ }^{1} \mathrm{BAP}+1 \mathrm{mg} / \mathrm{l}^{-1} \mathrm{GA} 3+250 \mathrm{mg} / \mathrm{l}^{-1} \mathrm{CH}$ " increased significantly the shoot length and no. of nodes/shoot. Regarding the jojoba genotypes, "Hail-B" showed the highest Shoot length, Shoot formation, number of leaves/shoot and no. of nodes/shoots, while Al-Madinah produced the least days to bud sprouting.

\section{Acknowledgement}

This project was funded by King Abdulaziz City for Science and Technology (KACST) under grant no. (AT-12-12). The authors, therefore, acknowledge with thanks King Abdulaziz City for Science and Technology (KACST) for the generous and full financial support for the research experiment.

\section{References}

Agrawal V., Prakash, S. and Gupta, S.C. (2002) Effective protocol for in vitro shoot production through nodal explants of Simmondsia chinensis, Biol. Plant., 45: 449453.

Aly, M.A., Amer E.A., Al-Zayadneh, W.A. and Eldin, A.E. (2008) Growth regulators influence the fatty acid profiles of in vitro induced jojoba somatic embryos, Plant Cell Tissue Org Cult 93: 107-114.

Ash, G. J., Albiston, A. and Cother, E. J. (2005) Aspects of Jojoba Agronomy and Management, Advances in Agronomy, V. 85, Australia.

Bashir, M.A., Ahmad, M. and Anjum, M.A. (2006) Propagation of six promising jojoba strains through veneer grafting, Int. J. Agric. Biol., 8: 482-484.

Bashir, M.A., Rashid, H. and Anjum, M.A. (2007) In vitro shoot multiplication of six promising strains of jojoba (Simmondsia chinensis), Biotechnology, 6: 309-315.

Bashir, M.A., Anjum, M.A. and Rashid, H. (2008) In vitro propagation of some promising genotypes of jojoba
(Simmondsia chinensis), African J. of Biotech., 7 (21): 3878-3886.

Elhag, H., El-Olemy, M.M., Mossa, J.S., Tag-El-Din, S.S., Al-Zoghet, M.F. and Al-Alsheikh, A.M.A. (1998) In vitro propagation of Jojoba, Program Abstracts of Annual Conference on New Crops and New Uses: Biodiversity and Sustainability, Phoenix, Arizona USA.

Gaber, A., El-Maraghy, H.M., Aly, M.A., Rashed, N.A. and Gamal El-Din, A.Y. (2007) Induction of somatic embryogenesis and DNA fingerprinting of jojoba, Arab $J$ Biotechnol 10: 341-354.

Gomez, K.A. and Gomez, A.A. (1984) Statistical Procedures for Agricultural Research, $2^{\text {nd }}$ edition, John Wiley and Sons, New York, p. 680.

Heba Allah, A.M., El-Bahr, M.K., Adam, Z.M., Moursy, H.A. and Solliman, M.E. (2009) In Vitro Clonal Propagation of Jojoba (Simmondsia Chinensis (Link) Schn.), Australian Journal of Basic and Applied Sciences, 3 (4): 3128-3136.

Kaliamoorthy, S., Naidoo, G. and Achar, P. (2008) Micropropagation of Harpagophytum procumbens, Biol. Plant., 52: 191-194.

Lambardi, M. (eds.) (2013) Protocols for Micropropagation of Selected Economically-Important Horticultural Plants, Methods in Molecular Biology, vol. 11013, DOI 10.1007/978-1-62703-074-8 2, C Springer Science + Business Media New York (Chapter Two: Berta E. Llorente and Nancy M. Apóstolo In Vitro Propagation of Jojoba.

Llorente, B. E. and Apóstolo, N. M. (2010) Effect of different growth regulators and genotype on in vitro propagation of jojoba, Laboratorio de Cultivo de Tejidos Vegetales, Departamento de Ciencias Básicas, Universidad Nacional de Lujan, C.C. 221 (6700) Luján, Buenos Aires, Argentina.

Mousa, M.A.A. and Bakhashwain, A.A.S. (2014) Genotypic and Growth Regulator Combination Effects on in vitro Nodal Segments of Jojoba (Simmondsia chinensis (Link)), Life Science Journal; 11 (4).

Prakash, S., Agrawal, V. and Gupta, S.C. (2003) Influence of some adjuvants on in vitro clonal propagation of male and female jojoba plants, In Vitro Cell. Dev. Biol.-Plant, 39: $217-222$.

Ramy, R.H., Ashraf, B.A., Amani, E.K. and Mohammed, M.A. (2004) Anti-inflammatory effects of jojoba liquid wax in experimental models.

Reddy, M.P. and Chikara, J. (2010) Biotechnology advances in jojoba (Simmondsia chinensis), In: Ramawat KG (ed) Desert plants, Springer, Berlin.

Singh, A., Reddy, M.P. and Patolia, J. S. (2008) An improved protocol for micropropagation of elite genotypes of Simmondsia chinensis (Link) Schneider Discipline of 
Phytosalinity, Central Salt and Marine Chemicals Research Institute, Bhavnagar, Gujarat-364002, India.

Steel, R.G.D. and Torrie, J.H. (1984) Principles and Procedures of Statistics: A Biometrical Approach. McGraw Hill Book Int. Co., Singapore.

Tyagi, R.K. and Prakash, S. (2004) Genotypes and sex specific protocols for in vitro micropropagation and medium term conservation of jojoba, Biol. Plant., 48: 1923. 
تحسين تكوين الأفرع المتكونة من الزر اعة المعملية للقطع الساقية الدقيقة لطرز ور اثية من الهو هوبا عن تز اكيب منظمات النمو النباتية

\section{عمرو صلاح محمد ז'ا، مجدي علي موسى '،" وأحمد عبدالله باخشوين'}

قسم زراعة المناطق الجافة، كلية الأرصاد والبيئة وزراعة الدناطق الجافة، جامعة الملك عبدالعزبيز، جدة، المدلكة العربية السعودية، وقسم بحوث الزيتون وفاكهة المناطق شبة الجافة، معهد بحوث البساتين، مركز

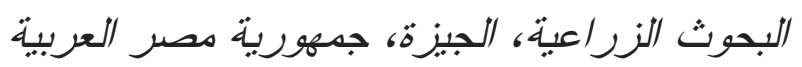

m_a_ahmed@yahoo.com*

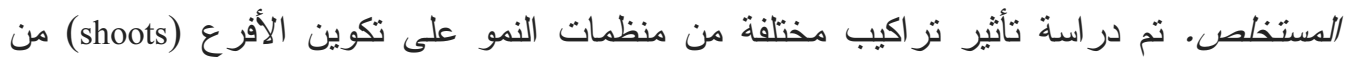

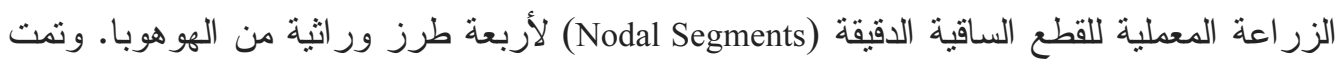

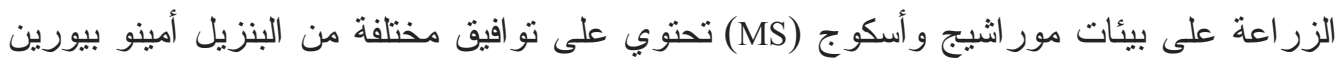

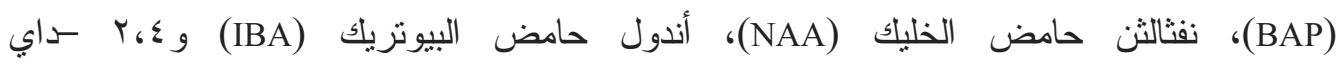
كلوروفينوكس حامض الخليك (2,4-D). تم تتفيذ التجارب باستخذام التصميم العشو ائي الكامل (CRD)

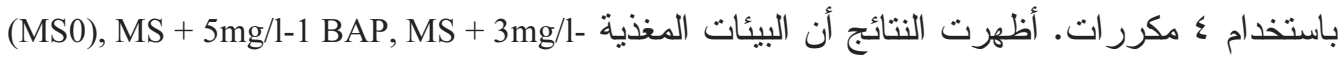
1 BAP + 5mg/l-1 IAA, MS + 5mg/l-1 BAP + 7mg/l-1 NAA and MS + 7mg/l-1 BAP + 7mg/l-1 أدت إلى نقص معنوي في عدد الأيام حتي انبثاق البراعم، وكنلك زيادة معنوية في نسبة البر اعم المنبثقة. البيئة المغذية MS + 7mg/l-1 BAP + 7mg/l-1 NAA أعطت أكبر عدد من الأوراق

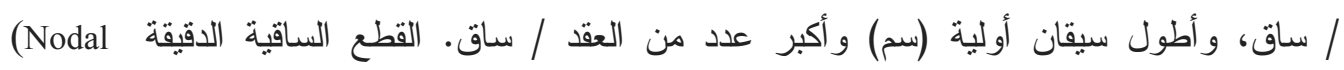

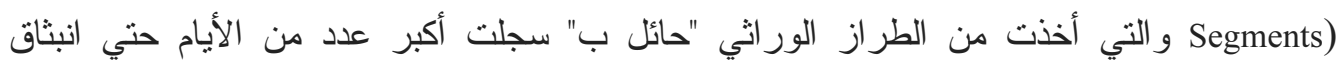

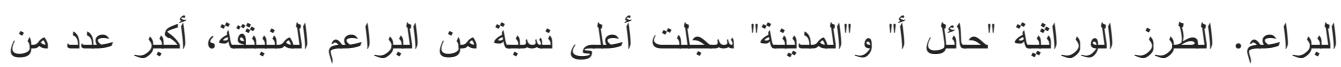

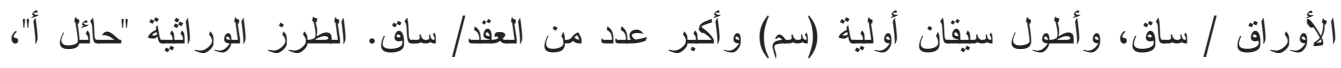

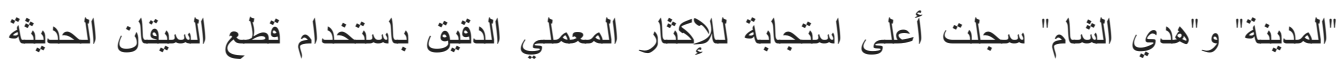

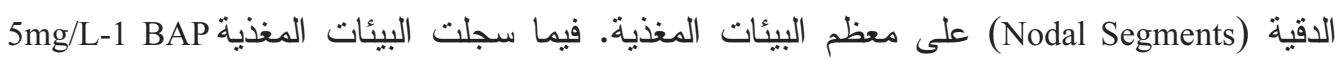

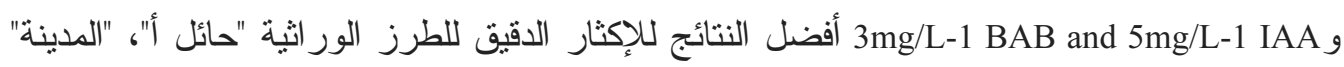
و "هدي الثام" باستخدام القطع الساقية الدقيقة (Nodal Segments). الكلمات الدالة: القطع الساقية الدقيقة، منظمات النمو، استحثاث السيقان، تكوين، الهوهوبا. 
